\title{
SYLLABIC CONSONANTS IN SLAVIC AND CELTIC LANGUAGES: THE MECHANISM OF ELEMENT EXTENSION
}

\author{
ANNA BLOCH-ROZMEJ
}

\section{Introduction}

This article focuses on the problem of syllabic consonants in the selected Slavic and Celtic languages, Polish, Czech and Irish in particular. Their phonological behavior will be analysed from the perspective of Government Phonology (henceforth GP), as defined in Harris (1994), Cyran (2003) and Gussmann (2007). Within the theoretical model of GP, the phonological structure of morphemes is constructed in terms of the licensing and governing relations between adjacent skeletal positions - the timing slots. The prosodic positions are then projected onto the syllabic constituents of nuclei (the heads of rhymes) and onsets. In such configurations, onsets are always dependent on their nuclear licensers. This situation is depicted in (1) below.

$$
\begin{array}{ll}
\text { a. Onset-nucleus licensing domain } & \text { b. morpheme structure } \\
&
\end{array}
$$
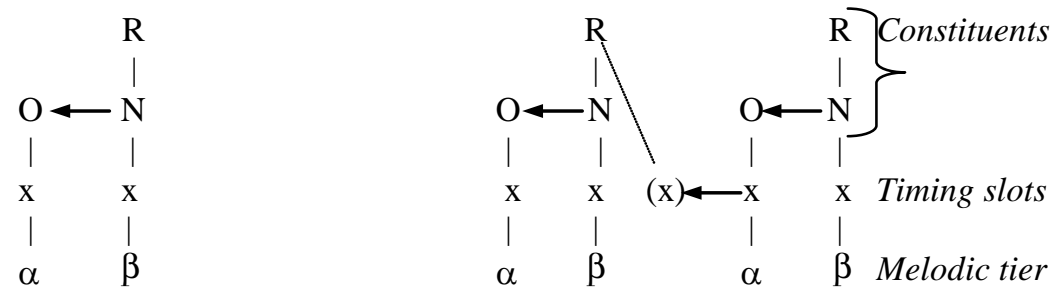

A specific proposal advocated in this article is that onset-nucleus domains are not only licensing domains but they also constitute the socalled extension domains. ${ }^{2}$ It will be further maintained that the phenomenon of the syllabic consonants can be analysed in terms of segment extension occurring within such onset-nucleus extension domains. It will be demonstrated that this solution effectively accounts for the relevant linguistic facts attested to in Polish, Czech, Slovak or SerboCroatian. In our analysis, the distinction between the syllabic and trapped consonants will be adopted from Scheer (2003) which, as will be proposed,

1 The structure below depicts an optional unit of the rhymal complement which, when present, has to be universally governed by the following onset point. Traditionally, such units were analysed as codas.

2 To be explained in detail in Section 2 below. 
derives from different lexical structures of either type. Apart from the available dictionary entries, we shall rely on the data provided by Scheer (2003), Dalewska-Greń (2002) and Rubach (1997). The evidence concerning the behavior of the syllabic consonants in the Slavic languages with respect to element extension will also be compared to the Irish situation which contributes to both the definition and further understanding of the element extension mechanism.

\section{Extension effects: theoretical basics}

As pointed out above, the model of Government Phonology recognizes the existence of a universal link between onsets and their nuclei, which stems from the operation of the Onset Licensing Principle (Kaye, Lowenstamm and Verrgnaud 1985). In terms of prosody, a nuclear licence enables an onset position to occupy its space within a given phonological string as well as perform further licensing responsibilities, for example towards possible complements. As far as its phonetic manifestation is concerned, an onset point receives its autosegmental licensing (a-licensing) potential from the nucleus to its right, which regulates the attachment of elements to its slot. Apparently then, an onset as a phonological entity is completely dependent on its nuclear licenser.

In what follows, we shall look into the phonological behavior of nuclei whose domain of impact seems to extend both leftwards and rightwards from their locus. In consequence, at least in some languages, nuclei exercise the right to influence the prosodic space that not only immediately precedes but also immediately follows them. The bi-directional nature of nuclear impact has been diagrammed in (2) below:

Range of nuclear impact

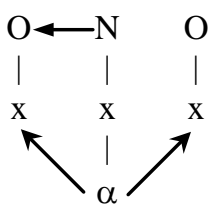

The figure in (2) depicts the range of influence that a nucleus can exert on either side of its segment. The impact is both prosodic and melodic in nature in the case of the preceding onset and only melodic with respect to the unit that follows it. Bearing in mind the path of distribution of the autosegmental licensing potential within a phonological domain (see the diagram in (3) below), we shall further propose that the head nucleus, which constitutes the ultimate source of all the potential available within a given domain, will enjoy the greatest extension capacity. The head of the 
domain will not be licensed by any other position in order to execute element extension. All the remaining nuclei in a given domain will receive authorisation to extend elemental material rightwards from their licensers. ${ }^{3}$

\section{Distribution of the a-licensing potential within a phonological domain}

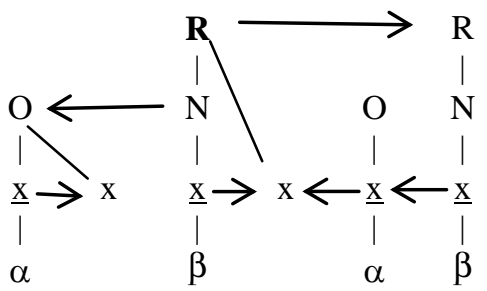

$\boldsymbol{R}$ is the head of the domain

Since the nucleus incapacitates the onset point to sustain the melodic content present in the melodic plane, it can also be expected that the nuclear position should have access to the onset elements. What is meant here is the ability of the nucleus to license the relevant primes both under the onset's and its own position. In this way, the execution of the licensing potential of the nuclear point results in a prime being allowed to contribute to the manifestation of both the nuclear and onset segments.

With respect to element extension, the following possibilities are theoretically available. Compare the two structures in (4a) and (4b) below:
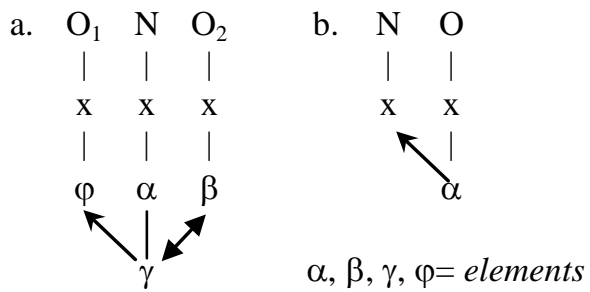

(4a) represents element sharing in which a prime $\gamma$, lexically specified in the nucleus, extends its domain of interpretation either rightwards or leftwards to include the neighboring onset position. Rightward element extension has been attested in German where the nucleus spreads its backness onto the following consonants, e.g. in Dach [dax] 'roof, sg.' . Leftward spreading occurs in Polish where high front vowels are capable of palatalising preceding onset segments, as in kot/koci [kot]/[kotci]

3 The theory of GP assumes that elements are the primitive units of melodic structure. They have unique phonetic interpretations and can amalgamate to build more complex segmental structures. 
'cat/gen.sg.'. ${ }^{4}$ At this point, we should recall element spreading in Connemara Irish, where the extension takes place leftwards from an onset to the preceding nucleus, for example in corc [kork] coirc [ker'k'] 'plug/pl.' Thus, the situation depicted in (4a) allows for the bi-directionality of element extension, depending on language. The structure depicted in (4b), in turn, assumes that an element is lexically specified in the onset and extends leftwards to the empty nuclear position. Such an extension operation targeting an empty nucleus can be regarded as a strengthening procedure that supports an empty position which is supposed to discharge its licensing responsibilities further leftwards. The option illustrated in (4b) will be implemented in the analysis of the syllabic consonants.

\section{Syllabic consonants}

The effect of element extension is most clearly discernible in the case of the so-called syllabic consonants. The archetypical syllabic is a vowel. Most languages have no other kind and all languages possess them. As for consonants, obstruents are more disfavored than resonants. Some languages have both syllabic resonants and syllabic obstruents, e.g. Arabic, French, Chinese, Mexican Spanish or Russian. However, Irish, beside English or Czech, features among those languages that possess only syllabic resonants. Interestingly, syllabic obstruents only can be found in Sierra Nahuat or Wichita (Bell 1978: 158). It is fairly common to find that the syllabic consonants occur largely in grammatical particles and affixes, as in Swahili. However, they also commonly occur without restriction to syntactic categories, as in Egyptian Arabic or Czech. It is noteworthy that the creation of a syllabic consonant is normally conditioned by the prior presence of a vowel. A syllabic segment comes into being once the vowel has undergone elision. Another feature characterising such segments is that phrase, word and morpheme boundaries play a significant role in the creation of syllabic consonants. Syllabic consonants tend to occur in unstressed positions. Yet, their presence under stress is by no means rare, as in English, Czech or Koryak. A contrast in length in syllabic consonants occurs but rarely, even at the phonetic level. Thus, for [1], some length contrast can be found in Slovak, as in tlsty 'thick' vs. tlk 'pestle' and for [r] in Slovak, Slovenian and Serbo-Croatian.

The traditional SPE-based approach to such segments was to treat them as consonants in the vocalic function. Accordingly, such units were represented as belonging to the nucleus of the syllable (e.g. Clements 1990, Kenstowicz 1994, Blevins 1995 and Hall 2000). Also within GP, the

4 Palatalisation in Polish constitutes a lot more complex phenomenon than this simple observation might suggest. For an in-depth study of this issue within GP, see Gussmann (2007). 
syllabic consonants have been analyzed as projected to the nuclear constituent (e.g. in the analysis of English syllabic [l] or [n], as in kettle or button in Harris 1994a). The opposite stance is taken by Scheer (2003) who argues that such an understanding of syllabicity 'violates the fundamental principle of autosegmental phonology'. This principle requires that segmental consonanthood and vowelhood should not be dependent on some inherent property of the melody, but must be determined by the syllabic constituent to which a given expression is linked. Consequently, the palatal prime I associated with the onset position will surface as a glide but it never obtains consonantal manifestation when attached solely to the nuclear slot. The analyses that fall in line with the autosegmental understanding of syllabicity as well as vocalic and consonantal dimensions, distinguish between two alternative ways of representing the syllabic consonants. In both interpretations, a segment is distinctively associated with an onset point but some assume it to spread to the preceding nucleus (e.g., Wiese 1996, Harris 1994), while others believe it to extend to the nucleus that follows (e.g., Rowicka 1999, Rennison 1999, Blaho 2001, Afuta 2002). The two options are depicted in (5a) and (5b) respectively:

\section{The syllabic consonant structures}
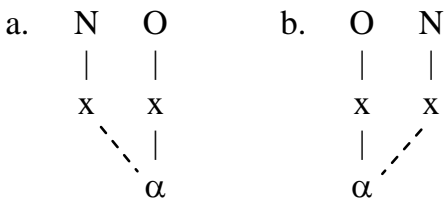

The evidence on the behavior of the syllabic consonants, provided by Slavic languages, indicates that, at least in this family, the representation offered in (5a) is the correct one. ${ }^{5}$ This conclusion, formulated in Scheer (2003), is based on the comparison of the syllabic consonants occurring in Czech, Slovak and Serbo-Croatian (e.g. trvat (Czech)) with trapped ones found in Polish. ${ }^{6}$ The latter type can be exemplified with Polish items in

5 The evidence quoted in Dalewska-Gren (2002) indicates that the syllabic coronal $[\mathrm{r}]$ is found in Serbo-Croatian, Macedonian, Czech and Slovak, whereas the syllabic [l] occurs in Czech and Slovak native words, while in Macedonian and Serbo-Croatian only in borrowings. In Macedonian, in fact, the consonantal cluster is split by an epenthetic vowel (see (6c)).

6 The trapped consonants in Polish have been subject to detailed analyses in, among others, Bethin (1984), Rubach (1996, 1997a,b) and Rubach and Booij (1990a, b). On Rubach's analysis, they are treated as extrasyllabic but, as Scheer (2003) argues, such a conclusion runs counter the generally accepted 'peripherality condition' requiring that 'extra-X objects may occur only at the edge of words' (Roca 1994: 213). As a result, 
(6a), while the syllabic [r] and [l] in the other Slavic languages are subsumed under (6b) and (6c) (Dalewska-Greń 2002: 88-91):

(6) a. Trapped C in Polish

$\begin{array}{ll}\begin{array}{l}\text { drwal } \\ \text { trwać }\end{array} & \begin{array}{l}\text { 'lumberjack' } \\ \text { 'to last' } \\ \text { trwonić }\end{array} \\ \begin{array}{l}\text { 'to squander' } \\ \text { 'to tease, deride' } \\ \text { drgać }\end{array} & \text { 'to vibrate' } \\ \text { b. Syllabic [r] in Slavic lgs } & \text { c. Syllabic [l] in Slavic lgs. } \\ \text { krk, prst, tvrdý (Czech) } & \text { vlk, vlna (Cz) } \\ \text { trpiet', vrch (Slovak) } & \text { hlboký (Sl) } \\ \text { крка, врба (Macedonian) } & \text { [ansambəą] (Mac) } \\ \text { prst, srce, brdo (Serbo-Croatian) } & \text { bicikl, artikl (S-C) }\end{array}$

As pointed out in Scheer (2003), both segment types are historically related and are found in the same positions within words having the same meaning. Nonetheless, a closer look at their behavior reveals significant differences which can be summarised as follows: ${ }^{7}$

Syllabic Consonants (SC)
May bear stress (e.g. Cz tr'vat)
[r, l] in Czech occur under stress, as
opposed to [m]
Count in poetry
In case a vowel-zero alternation
occurs to their left, the zero alternant
is found before SC (e.g., Czech
odẹbrat vs. odbirat 'to take away')

Trapped Consonants (TC)

May not bear stress (e.g.

Polish trwa'ć)

Do not count in poetry

In case a vowel-zero alternation occurs to their left, the alternation site is vocalised before $T C$ (e.g., Polish rozedrgać 'to become vibrating')

Vowel-zero alternations occurring before SCs and TCs constitute the most significant argument for recognizing the difference between the two types of segments. The syllabic consonants seem to be left-branching since the nucleus which precedes them is able to govern the prefix-final nucleus (ode $b \emptyset_{1}$ rat vs. od $\underline{\sigma}_{2}$ birat where [i] governs $\emptyset_{2}$ ). The prefix-final site in Polish, however, exhibits vocalisation effects, which indicates that the nuclear position preceding TCs is unable to govern. It can be concluded then that in a word such as roze- $d \varnothing_{1} r \varnothing_{2} g a c$, the trapped [r] branches on $\emptyset_{2}$, which then governs $\emptyset_{1}$. Consequently, it can be proposed that 'SCs are left-

extrasyllabic, extrametrical or extraprosodic units are not expected to occur domaininternally.

7 The table is based on Scheer (2003). 
branching, while TCs are right-branching' (Scheer 2003). This conclusion finds support in diachronic evidence which reveals that both SCs and TCs resulted from the loss of Common Slavic (CS) yers, the former involving the loss of the preceding vowel, while the latter the following one. Compare CS pbrvz, vblna, vblkb which developed into Czech prvý, vlna, vlk with CS trbvati, gromĕti, klbn that became trwać, grzmieć, klnę in Polish (Scheer 2003).

In terms of phonological representation, the structure depicted in (5a) above will be characteristic of syllabic consonants, whereas that in (5b) will underlie the realisation of the trapped consonants in Polish. Such a conclusion forces us to modify our understanding of syllabicity which has to be perceived as deriving solely from the leftward onset extension. Its extension rightwards will then define a phonetically trapped segment. In both cases, the nucleus adjacent to the onset is lexically empty but still liable to both phonological and, consequently, phonetic anchoring of the onset material undergoing extension. As for the syllabic consonant structure, it is noteworthy that the Slavic situation corresponds to that already mentioned for German. To sum up, it should be borne in mind that segment extension is a mechanism whose employment and directionality is a language-specific property. We propose that it can be regarded as a form of nuclear support which is effected either under Onset-Nucleus or internuclear licensing.

As was observed in the opening lines of this section, the function of the syllabic consonants is performed primarily by sonorants. However, it is possible to furnish evidence demonstrating that sibilants can also be used by languages as extension material. Thus, onset elements are allowed to exert impact on the preceding nuclei as well as those that follow them. Further evidence supporting this statement comes from Connemara Irish.

\section{Syllabic consonants in Irish}

As already indicated, Irish belongs to the group of languages that possess only resonants in the syllabic function. In the languages of the world syllabic nasals are greatly favored over liquids. This preference can certainly be observed in Irish. The language that possesses only syllabic liquids is Lendu, whereas Irish has both types of syllabics in which it resembles English, Czech, Moroccan Arabic or French. There are a few hints that in the class of laterals the darker ones are more prone to be syllabic. For instance, in Russian, as observed in Avanesov (1968), only the 'hard' [l] becomes syllabic. However there is one clear case of a palatal $[K]$ occurring as the only syllabic lateral of the language, namely Ring Co. Irish. In this dialect, the original unpalatalised lateral became $\left[\gamma^{\mathrm{w}}\right]$. As for 
nasals in the syllabic function, Irish possesses only the coronal nasal, to the absence of the syllabic bilabial and velar segments. In this respect, Irish resembles Norwegian and Navaho. The obvious way for a language to develop only one kind of syllabic nasal is for it to have just this nasal in the context of syncope. This nasal must also resist assimilation. Thus, syllabic nasals in Ring Co. Irish occur as variants finally after homorganic consonants by the loss of the preceding vowel schwa. A tabulation of the final sequences of the form $-\mathrm{C}_{1} \partial \mathrm{C}_{2} \#$ from the many citations from Breatnach (1947) shows that final [m] is rare in this context and is not found at all after a labial consonant. Indeed, no words were found where $\mathrm{C}_{1}$ and $\mathrm{C}_{2}$ were labial.

Having quoted a number of facts concerning the occurrence of the syllabic consonants in Irish, it has to be summarised that the segments do not occur in all dialects of Irish. In the majority of dialects, consonant+resonant sequences that are followed by a morpheme boundary are split up by an epenthetic vowel. However, as noted above, syllabic nasals are attested to in Ring Co. Irish. Let us repeat the context for the development of the syllabic nasal:

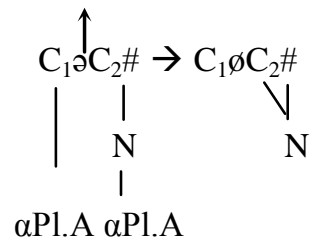

(Pl.A=place of articulation)

Thus, the picture in (8) depicts a situation where the nasal projected to the word-final onset captures the empty nuclear position before it. As we see, the kind of syllabic consonant structure that we attest in Irish is the (5a) kind. In this configuration, onset material is extended leftwards from the onset to the preceding nucleus.

\section{Nasality extension in Irish}

In what follows we want to maintain that the extension of melodic material can target also phonetically filled positions. However, the operation preserves the properties of being bi-directional and exclusively local, which distinguishes it from spreading. Our aim is to further substantiate the claim that even though no licensing relationship exists between a nucleus and the following onset, their interaction is still possible. More specifically, we intend to demonstrate that onset melodic material can exert direct impact on the interpretation of preceding nuclear melodies.

A process that clearly seems to testify to the existence of prime extension in the $\mathrm{N}-\mathrm{O}$ sequences is that of vowel nasalisation. As indicated 
in Maddieson (1984), over 99\% of languages possess nasalised vowels or consonants. What is more, coarticulatory nasalisation is found in virtually all languages (Beddor 1993). Consider the data from Connemara Irish provided in (9) below.

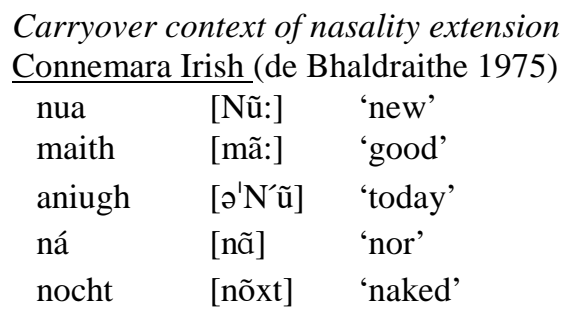

The bi-directional nature of nasality extension can be demonstrated to occur in the Connemara variety of Irish where the propagation of the nasal property can be effected both leftwards and rightwards from the distinctive locus of the $\mathbf{N}$ prime. ${ }^{8}$ The transmission of the nasality element onto vocalic expressions serves as a clear indication of two processes capable of targeting nasal segments in Irish: denasalisation and vocalisation. Both of these developments are illustrated in (10a) and (10b) below:

\begin{tabular}{|c|c|c|c|}
\hline \multicolumn{3}{|c|}{ a. n-denasalisation } & b. vocalisation \\
\hline gnaoighthe & [grĩ:] & 'business/pl.’ & comhla [kũ:Lə] 'door' \\
\hline cnaipe & [kræ̃:p’ə] & ‘button’ & amhlaidh [aũLə] 'thus' \\
\hline mná & [mrã:] & 'women’ & reamhar [raũr] \\
\hline cnoc & [krũk] & 'hill’' & \\
\hline
\end{tabular}

The items listed ${ }^{9}$ in (10a) depict the operation of $\mathbf{N}$-extension from the nasal segment $[\mathrm{n}]$ onto the vowel that occurs to its right. More precisely, the nasal prime becomes delinked from the onset slot by which it was originally licensed due to the process of nasal lenition after plosives. Simultaneously, $\mathbf{N}$ is captured by the position of the following vowel, thus nasalising it.

8 In GP, nasality is encoded by means of the element $\mathbf{N}$.

9 The data come from de Bhaldraithe (1975). We abstain from issuing a complete analysis of the denasalisation process here. Yet, it should be remembered that the operation of nasal reduction in the context following plosives and [m], can be substantiated with such alternations as $s n[\mathrm{n}]$ eachta/an t-sn[r]eachta 'snow/of the snow', where the nasal present after the fricative in the first item alternates with [ $r]$ when the strident becomes replaced with [t] due to $t$-prefixation. For an extensive analysis of nasal lenition in Connemara Irish, see Bloch-Rozmej (1998). Similarly, we shall not specify all the arguments in favour of the vocalisation present in the items in (10b). For the discussion of this question, see de Bhaldraithe (1975) and Ó Siadhail (1989). 
The other column, in (10b), is intended to exemplify the working of $\mathbf{N}$ extension leftwards, involving the vocalic position preceding the nasal melody. With reference to the vocalisation process found in these items, the existence of alternations testifies to the presence of the consonant to the right of the nasalised vowel: reamhar [raũr] reimhre [raivr'ə] 'fat' 'fat'. The anticipatory kind of nasalisation can also be observed in such Irish words as:

$\begin{array}{lll}\text { annlann } & {[\tilde{a}: \mathrm{NLəN}]} & \text { 'sauce' } \\ \text { aimsir } & {\left[\tilde{x} \mathrm{~m} \int \mathrm{ir} \text { ] }\right.} & \text { 'weather' } \\ \text { láimh } & {[\text { Lã:v'] }} & \text { 'hands' } \\ \text { am } & {[\tilde{a}: \mathrm{m}]} & \text { 'time' }\end{array}$

An important conclusion that emerges from the presentation of the above data is that the elemental content of the onset melody is capable of exerting influence on the vocalic segment preceding it. In fact, whether remaining attached to its onset point or delinked from it, e.g. due to the process of nasal lenition, the nasal prime can become extended either leftwards or rightwards. When we compare the behavior of the nasal element to the palatal I in Irish, for instance, the propagation of the latter can be effected only leftwards from a position it is attached to. Thus, when linked to a given slot, I may not affect the melodies to its right. However, at least in Connemara Irish, $\mathbf{N}$-extension is restricted to local contexts only. There are obviously systems where the nasal prime participates in long-distance relationships. Similarly, there are languages, in which, unlike in Irish, the propagation of I can be limited to its adjacent sites only. Thus, summing up, the employment of the extension mechanism, its directionality and range of impact within phonological domains appear to be languagespecific properties.

\section{Conclusion}

We have seen that some languages exhibit the phenomenon of element extension. The extension of primes also falls in the purview of an interpretive component, i.e. it concerns the manifestation of a particular element over a given part of representation. It should be viewed as a local effect whereby a prime that is lexically specified in a given position extends its domain of influence either rightwards or leftwards of its locus. The data from several of languages discussed in the previous sections reveal that element extension involves onset primes whose impact radiates away from their skeletal position, thus being able to affect the nuclear melodies either to their left or to their right. In contradistinction to spreading, such effects are characterised by apparent lack of direct 
connection with licensing. Nevertheless, such a connection, although not immediately obvious, does exist. The necessity of combining extension with licensing is enforced by the Extension Principle (Bloch-Rozmej 2008) which requires that the extending prime should receive support from the nucleus.

In the case of rightward element extension, the nucleus affected happens to be the licenser of the relevant onset - the source of the extension material. In this situation (the trapped consonant structure), element extension can be perceived as a nucleus-strengthening mechanism, set in motion as a language-specific tool of increasing the licensing capacity of weaker nuclei. The rightward element extension domain overlaps with an onset-nucleus licensing domain. As for the leftward prime extension, an onset element extends its interpretation to the preceding nuclear melody. It is noteworthy that no licensing relation binds an onset and a nucleus before it.

Hence, to satisfy the requirements of the Extension Principle, the extending prime has to be supported by the nuclear licenser to the right of the onset in question. This type of element extension is attested to in the syllabic consonant kind of structure. The two respective TC and SC structural configurations are repeated below in (12a) and (12b) respectively:

\section{a. TC structure}

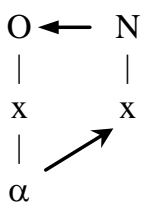

b. SC structure

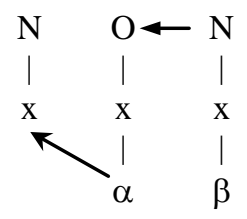

John Paul II Catholic University of Lublin, Poland 


\section{References}

Afuta, P., 2002, 'Representation of Syllabic Consonants and Statement of a Final Site in Yiddish', poster at the 10th Manchester Phonology Meeting.

Avanesov, R.I., 1968, Russkoye literaturnoye proiznosheniye, $4^{\text {th }}$ ed., Moscow: Izdatel'stvo Prosveščeniye.

Beddor, P., 1993, 'The Perception of Nasal Vowels', in: Huffman, M.K., \& Krakow, R. A., eds., 171-196.

Bell, A., 1978, 'Syllabic Consonants', in: Greenberg, J., ed., 153-201.

Bethin, Ch., 1984, 'Voicing Assimilation in Polish', International Journal of Slavic Linguistics and Poetics 29, 17-32.

Blaho, S., 2001, 'The Representation of Slovak Syllabic Consonants in Strict CV', The Odd Yearbook 6, 3-24.

Blevins, J., 1995, 'The Syllable in Phonological Theory', in: J. Goldsmith, ed., Handbook of Phonological Theory, 206-244.

Bloch-Rozmej, A., 1998, Element Interactions in Phonology. A Study in Connemara Irish, Lublin: Redakcja Wydawnictw KUL.

Bloch-Rozmej, A., 2008, Melody in Government Phonology, Lublin: Wydawnictwo KUL.

Breatnach, R. B., 1947, The Irish of Ring, Co. Waterford, Dublin: Dublin Institute for Advanced Studies.

Clements, G. N., 1990, 'The Role of Sonority Cycle in Core Syllabification’, in: Kingston, J. \& Beckman, M., eds., 283-333.

Cyran, E., 2003, Complexity Scales and Licensing Strength in Phonology, Lublin: Wydawnictwo KUL.

Dalewska-Greń, H., 2002, Języki stowiańskie, Warszawa: Wydawnictwo Naukowe PWN.

de Bhaldraithe, T., 1975, The Irish of Cois Fhairrge, Co. Galway. A Phonetic Study, Dublin: Dublin Institute for Advanced Studies.

Greenberg, J., ed., 1978, Universals of Human Language. Vol. 2: Phonology, Stanford: Stanford University Press.

Gussmann, E., 2007, The Phonology of Polish, Oxford: Oxford University Press.

Hall, T. A., 2000, Phonologie. Eine Einführung, Berlin and New York: de Gruyter.

Harris, J., 1994, English Sound Structure, Oxford: Blackwell.

Kaye, J., Lowenstamm, J. \& Vergnaud, J.-R., 1985, 'The Internal Structure of Phonological Elements: a Theory of Charm and Government', Phonology Yearbook 2, 305-328.

Kenstowicz, M., 1994 Phonology in Generative Grammar, Oxford: Blackwell. 
Maddieson, I., 1984, Patterns of sounds, Cambridge: Cambridge University Press.

Ó Siadhail, M., 1989, Modern Irish, Grammatical structure and dialectal variation, Cambridge: Cambridge University Press.

Rennison, J. R., 1999, 'Syllables in Western Koromfe', in: van der Hulst, H. \& Ritter, N., eds., 311-347.

Roca, I., 1994, Generative Phonology, London: Routledge.

Roca, I. ed., 1997, Derivations and Constraints in Phonology, Oxford: Clarendon.

Rowicka, G., 1999, On Ghost Vowels. A Strict CV Approach, Hague: Holland Academic Graphics.

Rubach, J., 1996, 'Nonsyllabic Analysis of Voice Assimilation in Polish', Linguistic Inquiry 27, 69-110.

Rubach, J., 1997a, 'Polish Voice Assimilation in Optimality Theory', Rivista di Linguistica 9, 291-342.

Rubach, J., 1997b, 'Extrasyllabic Consonants in Polish: Derivational Optimality Theory', in: Roca, I., ed., 551-581.

Rubach, J. \& G. Booij, 1990a, 'Syllable Structure Assignment in Polish', Phonology 7, 121-158.

Rubach, J. \& G. Booij, 1990b, 'Edge of Constituent Effects in Polish', Natural Language and Linguistic Theory 8, 427-463.

Scheer, T., 2003, 'Syllabic and Trapped Consonants in Slavic: Different but still the Same', paper presented at Formal Description of Slavic Languages 5, Leipzig, 26-28 November 2003.

Wiese, R., 1996, The Phonology of German, Oxford: Clarendon Press. 